\title{
Post-Operative Analgesic Efficacy of Nalbuphine Compared with Tramadol for Lower Limb Orthopaedic Surgeries-An Observational Study
}

\author{
Nithin Sathyan ${ }^{1}$, Surya S.H. ${ }^{2}$, Sajil M.S. ${ }^{3}$, Sreesabari S. ${ }^{4}$ \\ 1,2, 3,4 Department of Anaesthesiology, Travancore Medical College, Kollam, Kerala, India.
}

\section{ABSTRACT}

\section{BACKGROUND}

Presence of pain is as old as that of humankind. From ancient times, pain has followed surgeons as well as anaesthesiologists like a shadow which is not seperable. ${ }^{1}$ Postoperative pain is an acute pain which can affect nearly all organ functions and can leads to postoperative period morbidity and mortality. Pharmacological treatment using intravenous opioids is an effective and popular method to treat the pain. ${ }^{2}$ In this study the researcher compared the analgesic efficacy and side effects of intravenousNalbuphine and Tramadol in those patients undergoing Lower limb Orthopaedic procedures. To investigate the effect of Nalbuphine and Tramadol on post-operative pain and to compare the side effects among Nalbuphine and Tramadol group in patient admitted in Travancore Medical College, Kollam during the period from January 2019 to September 2019.

\section{METHODS}

This study was a prospective observational study. The study population comprises, 140 patients falling within the inclusion criteria who had given consent for participating in this study. Sub arachnoid block is commonly followed in our Anesthesiologydepartment for Lower limb orthopaedic procedures 3 to $3.5 \mathrm{ml}$ of $0.5 \%$ hyperbaricbupivacaine via $25 \mathrm{G}$ spinal needle. No analgesic or sedative will be given intra operatively.Patients who had received Injection Nalbuphine $0.15 \mathrm{mg} / \mathrm{kg}$ IV diluted till $10 \mathrm{ml}$ volume innormal saline and Injection Tramadol $2 \mathrm{mg} / \mathrm{kg}$ IV diluted till $10 \mathrm{ml}$ volume of normal salinewere grouped as $N(n=70)$ and $T(n=70)$ respectively. Post-operative pain was assessed usingVAS, onset of drug effect and duration of action of each dose of drug. Side effects of drugsassessed using the variables such as incidence of postoperative nausea and vomiting (PONV),Ramsay sedation scores, respiratory rate and Sp02. VAS score assessed initially every5 minutes till 15 minutes, then every 30 minutes till 2 Hrs, then $3 \mathrm{Hrs}$, 4 Hrs, 5 Hrs, 6 Hrs, $8 \mathrm{Hrs}, 12 \mathrm{Hrs}, 16 \mathrm{Hrs}, 20 \mathrm{Hrs}$ and $24 \mathrm{Hrs}$. Ramsay sedation scores, respiratory rate and $\mathrm{SpO} 2$ were assessed initially every 5 minute till 15 minutes, every 30 minute till 2 hours, then at $4 \mathrm{Hrs}, 6 \mathrm{Hrs}, 8 \mathrm{Hrs}, 12 \mathrm{Hrs}, 16 \mathrm{Hrs}, 20 \mathrm{Hrs}$ and $24 \mathrm{Hrs}$ duration.

\section{RESULTS}

From the results we found that with successive doses it Nalbuphine proven to be having significantly longer duration of analgesia than Tramadol after the third dose. Based on the VAS scores Group $\mathrm{T}$ is more effective in controlling pain initially, butlater on pain scores significantly less with Group $\mathrm{N}$ became more effective. Side effects likenausea and vomiting is comparable between two groups but incidence more in Group T.Respiratory depression side effects is also comparable between the two groups but incidencemore for Group N.

\section{CONCLUSIONS}

Nalbuphine $0.15 \mathrm{mg} / \mathrm{kg}$ can be an effective tool in the treatment of acutepostoperative pain in lower limb orthopaedic procedures. Both Nalbuphine and Tramadol canbe a good alternative in the multimodal therapy of acute postoperative analgesia.

\section{KEY WORDS}

Nalbuphine, Tramadol, Lower Limb Orthopaedic Surgeries, Sub Arachnoid Block
Corresponding Author:

Dr. Sajil M.S.,

Department of Anaesthesiology,

Travancore Medical College,

Kollam, Kerala, India.

E-mail: sajil-doc@yahoo.com

DOI: $10.14260 /$ jemds $/ 2022 / 45$

How to Cite This Article:

Sathyan N, Surya SH, Sajil MS, et al. Postoperative analgesic efficacy of nalbuphine compared with tramadol for lower limb orthopaedic surgeries-an observational study. J Evolution Med Dent Sci 2022;11(01):232-240, $10.14260 /$ jemds/2022/45

Submission 27-12-2021,

Peer Review 02-01-2021,

Acceptance 29-01-2021,

Published 31-01-2022.

Copyright (c) 2022 Nithin Sathyan et al. This is an open access article distributed under Creative Commons Attribution License [Attribution 4.0 International (CC BY 4.0)] 


\section{BACKGROUND}

Pain is an unpleasant sensory and emotional experience related with anactual or a potential damage to tissue, or described in terms of such damage devised by the International Association for the Study of Pain (IASP). ${ }^{3}$ The liberation of pain and suffering is one of the primary aims of medicine. Acute pain in postop is a multifaceted physiologic response to tissue injury, viscera distension, or disease. Factually, the treatment of postoperative pain has been assumed low importance by surgeons and anaesthesiologists. Consequently, patients formerly accepted pain as an unavoidable experience after surgeries. With the development of expanding awareness of the epidemiology and pathophysiology of pain, more consideration is being focused on the controlling of pain in an exertion to mend the quality of care and decrease postoperative morbidity and mortality. In contemporary practice, postoperative pain endures being a challenge for anesthesiologists. 4 The stoppage of pain during postop period is so important because it has the risk of transition to chronic pain state.

Postoperative pain is often ineffectively treated leading to a number of complications; therefore the pain of surgeries must be relieved absolutely.5,6 in current postoperative cares, this means real relief from pain, suffering, anxiety and sleeplessness. The outcome of the postoperative recovery may be significantly decreased by effective pain management. Real postoperative pain relief delivers mental and economic benefits and diminishes the onset of chronic pain syndromes more common with orthopedic procedures. 5,7

Irrespective of the accessibility of effective analgesic agents, 30 to $70 \%$ of patients continues to suffer severe postoperative pain. One of the serious deficits in pain management today is the under-treatment of postoperative pain. ${ }^{4}$ Techniques for postoperative analgesia consist of systemic analgesics such as non-steroidal anti-inflammatory drugs (NSAID) or opioids, incisional local anaesthetics, preemptive analgesia, multimodal analgesia, intra wound analgesics-NSAID or opioids, and cryoanalgesia. ${ }^{8}$ Here the researcher is comparing the efficacy of two drugs on postoperative analgesia.

Tramadol is a centrally acting analgesic with a low affinity for $\mu$-opioid receptors, ${ }^{9}$ additional monoaminergic activity through the inhibition of the neuronal uptake of serotonin and norepinephrine. ${ }^{10}$ The analgesic effect of Tramadol reported to be 10 times less when compared to morphine, 11 with less side effect profile,12 Unlike usual opioid analgesics, the use oftramadol not related with clinically important side effects like respiratory depression, constipation or sedation. In addition, analgesic tolerance has not been a serious problem during repeated administration, and neither psychological dependence nor euphoric effects are observed in long-term clinical trials. ${ }^{13}$

Nalbuphine hydrochloride is a synthetic opioid agonistantagonist with analgesic action and it belongs to phenanthrene series with duration of action 4-5 hours. It has structural relation with naloxone which is an opioid antagonist, and to the potent analgesic, oxymorphone. It can be used for the treatment of moderate to severe pain, pain relief during perioperative period and during childbirth. In patients with acute pain, the analgesic effectiveness is equivalent to morphine with a milligram basis. ${ }^{14}$ Compared to
Morphine, nalbuphine leads to less respiratory depression at large doses and it has little effect on arterial pressure. ${ }^{15}$

In humans the drug undergoes hepatic metabolism giving $N$-hydroxy-aceto-cyclo-butylmethyl-nor nalbuphine, the chief metabolite, and other hydroxylated derivatives. The hepatic clearance will be mainly dependent on blood flow to liver and hepatic extraction ratio is $0.5-0.7 .16$

Orthopaedic surgeriescan related to prolonged PACU stay due moderate to severeintensity of postoperative pain, unexpected admission and reduced patient satisfaction. ${ }^{17-20}$ Postoperative pain was one among the most common reasons for unanticipated admission, in which $57.6 \%$ of them were orthopaedic patients. ${ }^{21}$ This moderate to severe pain following orthopaedic procedures can persist up to postoperative day 3.22

Most orthopaedic procedures except for spine surgery are performed under regional anaesthesia. ${ }^{23}$ Regional anaesthesia is used in order to block the pain sensation in a specific area of the body. The patients do not suffer loss of consciousness and are aware of what is happening while feeling relaxed due to sedatives. The main advantage of regional anaesthesia in comparison to general anaesthesia is that, regional anaesthesia is used in extensive interventions affecting only the particular area that will undergo the surgery, while general anaesthesia inevitably affects the entire body. Regional anaesthesia canbe considered as a preferable method ofanalgesia after surgery. ${ }^{24}$

Spinal anaesthesia also known as subarachnoid anaesthesia is a form of local or regional anaesthesia, that involves injecting local anesthetics into the subarachnoid space. The injection is usually made in the lumbar region at the L2/3 or L3/4 space. Spinal anaesthesia has the benefit of simplicity, rapid onset of action, low failure rate, minimum drug dose, and admirable muscle relaxation, which makes it the procedure of choice for surgeries performed on the lower limbs, genitourinary surgery, hernia repair or and caesarean surgeries. 25

Depending on the local anaesthetics used, single-shot in spinal anaesthesia have a limited duration of action. Thus, a mixture of other analgesics is needed to relieve pain when the spinal block wears off. 26

The Aim of our study is to determine the effect of intravenous doses of tramadol and nalbuphine on the duration of post-operative pain and their side effects among the patients, who are posted for lower-limb orthopaedics surgery under spinal anaesthesia.

\section{Objectives}

1. To evaluate the post-operative analgesic efficacy of nalbuphine compared with tramadol for lower limb orthopaedic surgeries

2. To study the duration of action and analgesic effect of nalbuphine compared to tramadol.

3. To compare the side effects of tramadol and nalbuphine group.

\section{METHODS}

This was a prospective observational study conducted over a period of nine months from December 2018 to August 2019 
in the pre-anaesthetic check-up (PAC) clinic, Orthopaedic ward, Orthopaedic operation theatre and post anaesthetic care unit (PACU) of Travancore Medical College (TMC) Kollam. The need and aim of study were explained to the patients in detail and informed written consent was obtained in English / Malayalam from the patient before including the subject in the study.

\section{Study Sample \\ 140 (70 on single arm) \\ $N=Z^{2} p(1-p) / d^{2}=63.72$}

Prevalence is 21.4

$\mathrm{Z}$ is the normal deviate $=1.96, \mathrm{~d}$ is the precision $=10 \%(\mathrm{~d}=0.1)$, $\mathrm{p}$ is the proportion (percentage reduction of postoperative pain 5 min after giving tramadol) is $21.4 \%(\mathrm{p}=0.21)$ from a similar previous study by Kiran KS et al ${ }^{116}$. The minimum sample size required for this study is 64 on single arm and 128 patients' total.

\section{Inclusion Criteria}

1. Patients admitted for lower limb orthopaedic surgeries under ASA I and ASA II

2. All patients aged between $18-65$ years

3. Patients with $\mathrm{BMI}<30$

4. Duration of surgery $<150$ minutes

5. No contraindication to nalbuphine or tramadol

6. No contraindication for spinal anaesthesia

7. Patients giving informed consent.

\section{Exclusion Criteria}

1. Patients with comorbidities including severe hypertension, ischemic heart disease, renal orliver disorders

2. Patients with $\mathrm{h} / \mathrm{o}$ substance abuse

3. h/o receiving central nervous system depressants, monoamine oxidase inhibitors, tricyclic antidepressants, selective serotonin reuptake inhibitors, and warfarin; established respiratory depression; a history of hypersensitivity to study drugs; or not willing to participate in the study.

\section{Sample Selection}

Samples were selected from elective lower limb orthopaedic surgery cases posted at the Travancore Medical College, Kollam after they were found to satisfy the inclusion and exclusion criteria.

The purpose of the study was explained to the patients enrolled in this study. Demographic and hemodynamic data such as age, BMI, Heart Rate, Systolic blood pressure, Diastolic blood pressure, mean arterial blood pressure, respiratory rate and $\mathrm{SpO2}$ were noted down in the proforma. Patient's ASA status were also recorded. After the medical ethics committee approval and obtaining written informed consent, 140 patients with ASA physical status I, II, aged between 18 - 65 years who were scheduled for elective lower limb orthopaedic surgeries under spinal anaesthesia, according to inclusion and exclusion criteria were enrolled in the study. All patients will be given information about the nature of the study and anaesthetic technique. They were instructed to the concept of VAS to record pain in the preoperative day. A detailed pre-anaesthetic assessment was done prior to the scheduled surgery, and in the postop period the Anaesthesiologist was randomly given first dose of analgesic (either Injection Nalbuphine $0.15 \mathrm{mg} / \mathrm{kg}$ IV diluted till $10 \mathrm{ml}$ volume in normal saline or Injection Tramadol 2 $\mathrm{mg} / \mathrm{kg}$ IV diluted till $10 \mathrm{ml}$ volume of normal saline were grouped as $\mathrm{N}(\mathrm{n}=70)$ and $\mathrm{T}(\mathrm{n}=70)$ respectively) when patient VAS Score $>4$ and it is repeated every $8 \mathrm{hrs}$.

\section{Procedure for giving spinal anaesthesia}

The anaesthesia technique will be standardized for both the groups. Baseline heart rate (HR), systolic blood pressure (SBP), diastolic blood pressure (DBP), mean arterial blood pressure (MAP) respiratory rate and $\mathrm{SpO2}$ were recorded five minutes before spinal anaesthesia. All the patients will be preloaded with Ringer Lactate 10 -15millilitre/kilogram and pre-medicated with Tab Alprazolam $0.25 \mathrm{mg}$ orally on previous night. Before the surgery, patients will be educated about the use of VAS for pain assessment post-operatively, where 0 defines no pain, and 10 defines the maximum intolerable pain. Lumbar puncture was performed after skin infiltration with lidocaine $2 \%(2-3 \mathrm{~mL})$ by a single-injection technique using a midline approach at the L2-3 or L3-4 interspace with a 25-gauge needle with the patient in the lateral position. After free flow of cerebrospinal fluid, $3 \mathrm{~mL}$ of hyperbaric bupivacaine $0.5 \%$ was injected, and the patient was turned supine. Sensory block to T10 dermatome will be considered adequate for the surgery \& surgery will be performed after confirming the adequate blockade with proper height of analgesia. Fluid administration will be continued intra-operatively, fall in mean arterial pressure by $20 \%$ of baseline will be treated with fluid bolus and phenylephrine 50 microgram intravenously. Fall in heart rate by $20 \%$ of baseline will be treated with atropine $0.6 \mathrm{mg}$ intravenously. No analgesic or sedative will be given intra operatively.

Procedure for evaluation of pain and monitoring of the side effects of given drugs

After surgery the patients will be shifted to Post Anaesthesia Care Unit (PACU). First dose of analgesic was given when the VAS Score $>4$ and was repeated every 8 hours. Patients who had received Injection Nalbuphine $0.15 \mathrm{mg} / \mathrm{kg}$ IV diluted till $10 \mathrm{ml}$ volume in normal saline and Injection Tramadol 2 $\mathrm{mg} / \mathrm{kg}$ IV diluted till $10 \mathrm{ml}$ volume of normal saline were grouped as $N(n=70)$ and $T(n=70)$ respectively. Postoperative pain was assessed using VAS, onset of drug effect and duration of action of each dose of drug. Side effects of drugs assessed using the variables such as incidence of postoperative nausea and vomiting (PONV), Ramsay sedation scores, respiratory rate and Sp02.VAS score assessed initially every 5 minutes till 15 minutes, then every 30 minutes till 2 Hrs, then 3 Hrs, 4 Hrs, 5 Hrs, 6 Hrs, 8 Hrs, 12 Hrs, 16 Hrs, 20 Hrs and 24 Hrs. Ramsay sedation scores, respiratory rate and SpO2 were assessed initially every 5 minute till 15 minutes, every 30 minute till 2 hours, then at 4 hours, 6hours, 8hours, 12 hours, 16 hours, 20 hours and 24 hours duration. As the VAS again reaches $\geq 6$ was determined as the cut off for the need of 
extra-analgesic doses with paracetamol $15 \mathrm{mg} / \mathrm{kg}$ intravenously. The study drugs were given until effects like excessive sedation (Ramsay 3 or more) or respiratory depression (RR $<8$ or $\mathrm{SpO} 2<90 \%$ ) appear. Any patient who was developed side effects, excluded from the study.

\section{Statistical Methods}

Data were entered in Microsoft Excel data sheet and Statistical Package for the Social Science (SPSS; ver.20.0) was used for statistical analysis. Continuous data was represented as mean and standard deviation whereas categorical variables are present as number and percentages. Student's ttest and Mann-Whitney $U$ test were the test of significance to identify the mean difference between two groups.Categorical variables by Fisher exact test. The p-value $<0.05$ was considered as statistically significant. Observations were recorded both graphically and numerically.

\section{RESULTS}

Over a period of nine months, a sample of 140 patients undergoing elective Lower limb Orthopaedic surgeries under spinal anaesthesia in our hospital, meeting the inclusion criteria were selected for this study after obtaining proper informed written consent. Data were entered in Microsoft Excel data sheet and Statistical Package for the Social Science (SPSS; ver. 20.0) was used for statistical analysis. Continuous data was represented as mean and standard deviation whereas categorical variables are present as number and percentages. Student's t-test and Mann-Whitney U test were the test of significance to identify the mean difference between two groups.Categorical variables by Fisher exact test. The p-value $<0.05$ was considered as statistically significant. Observations were recorded both graphically and numerically.
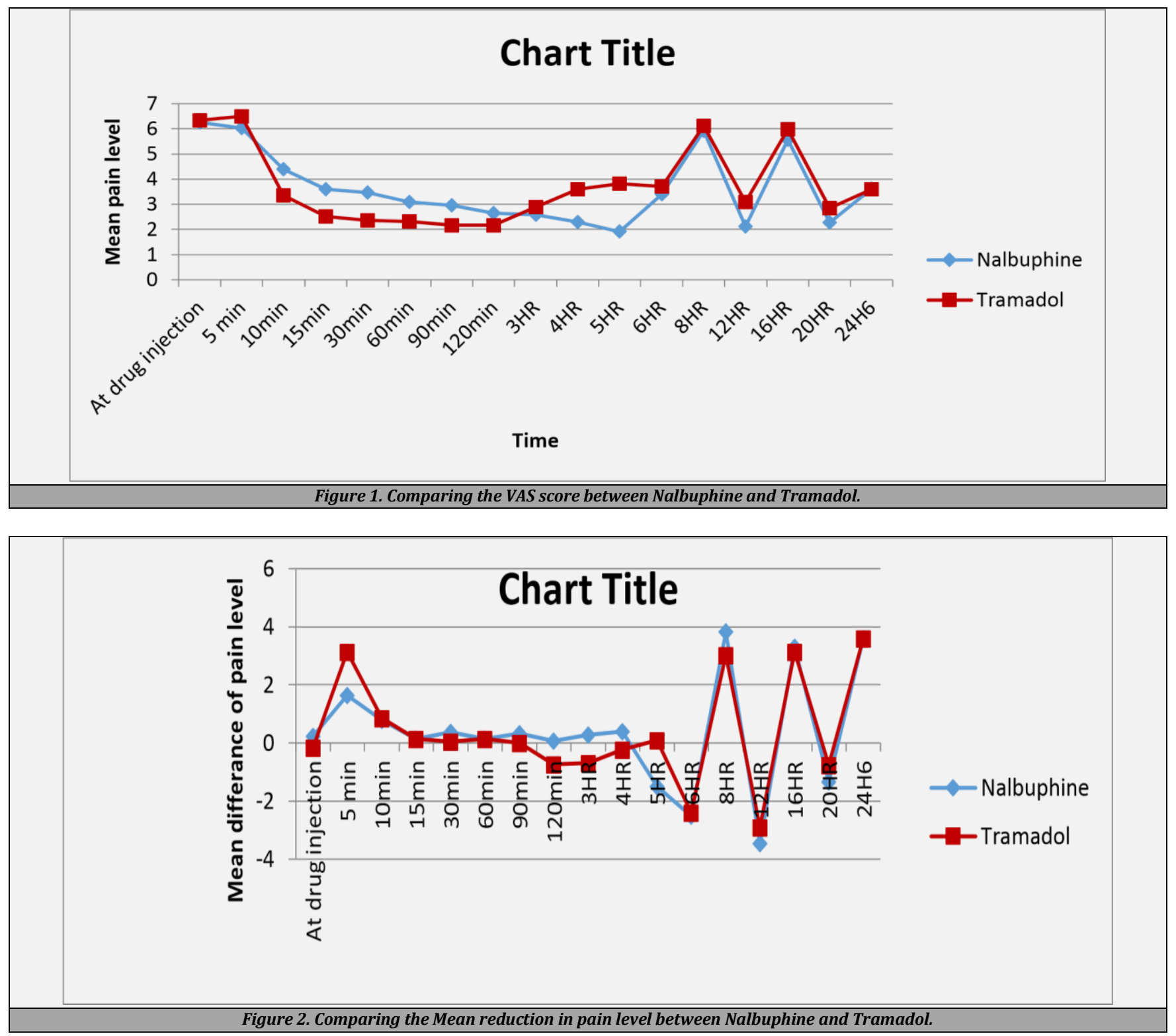


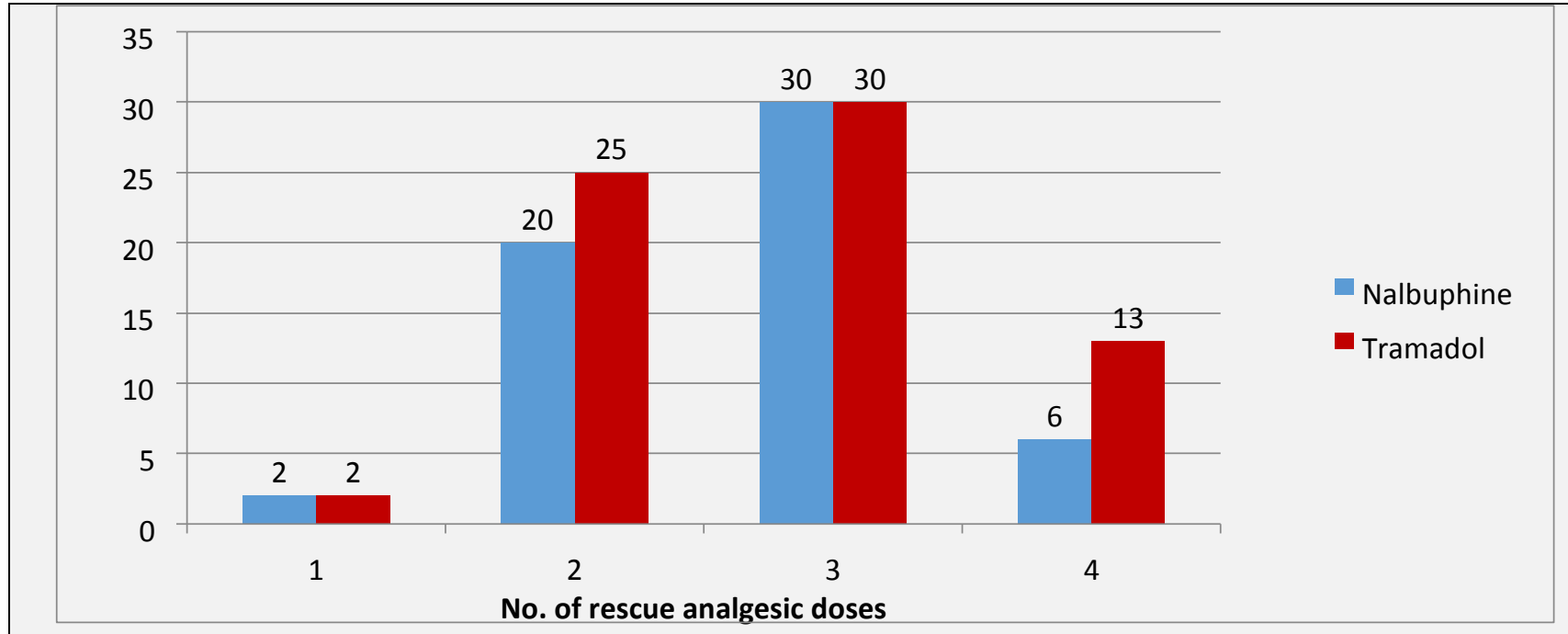

Figure 3. Showing the comparison between Nalbuphine and Tramadol with respect to requirement of number of analgesic doses.

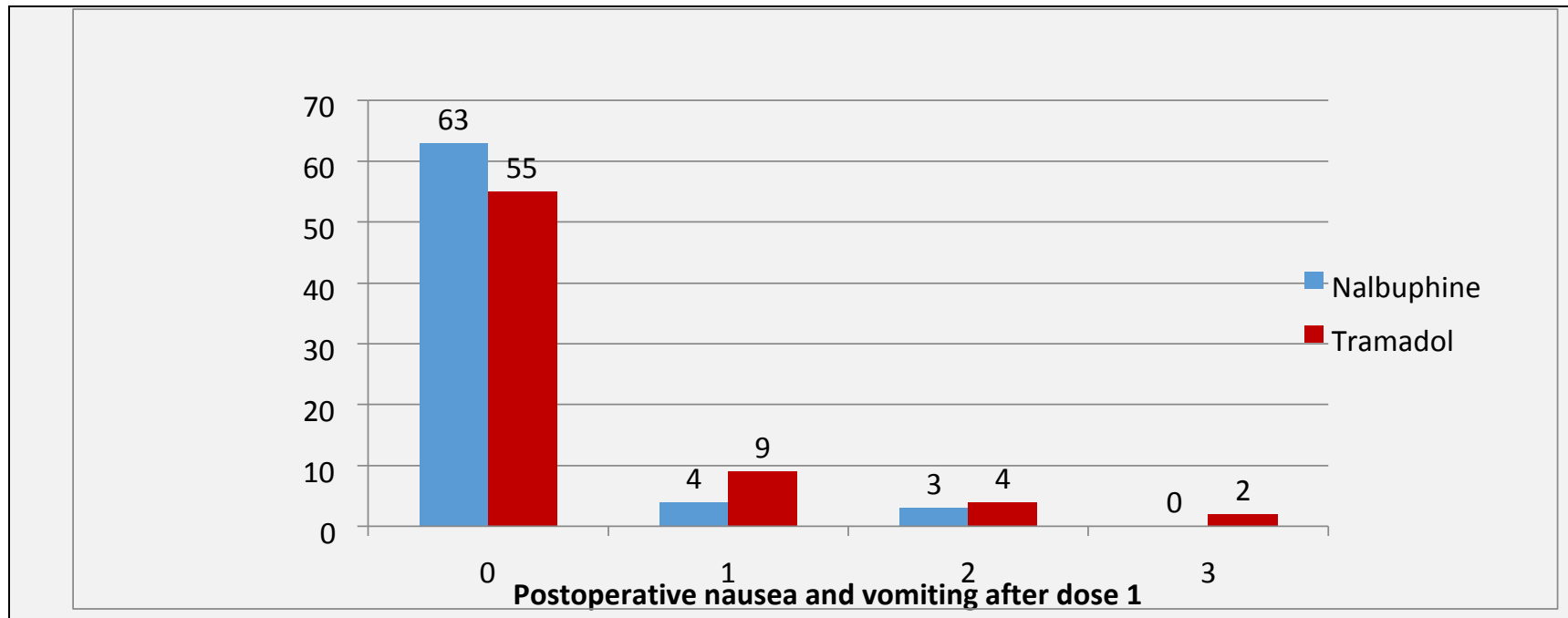

Figure 4. Showing the comparison between Nalbuphine and Tramadol with respect to postop Nausea and Vomiting after first dose of analgesia.

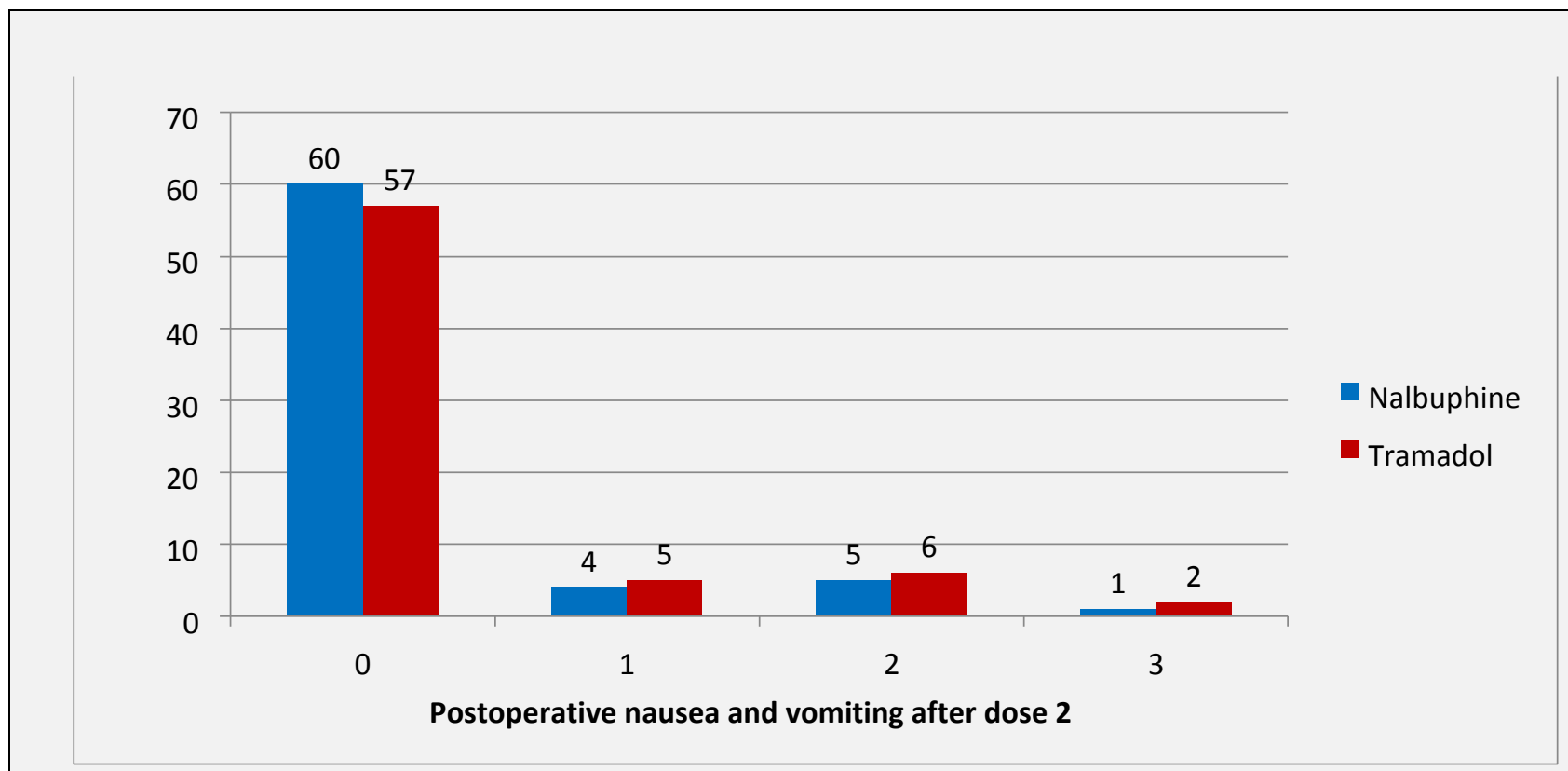

Figure 5. Showing the comparison between Nalbuphine and Tramadol with respect to postop Nausea and Vomiting after second dose of analgesia. 

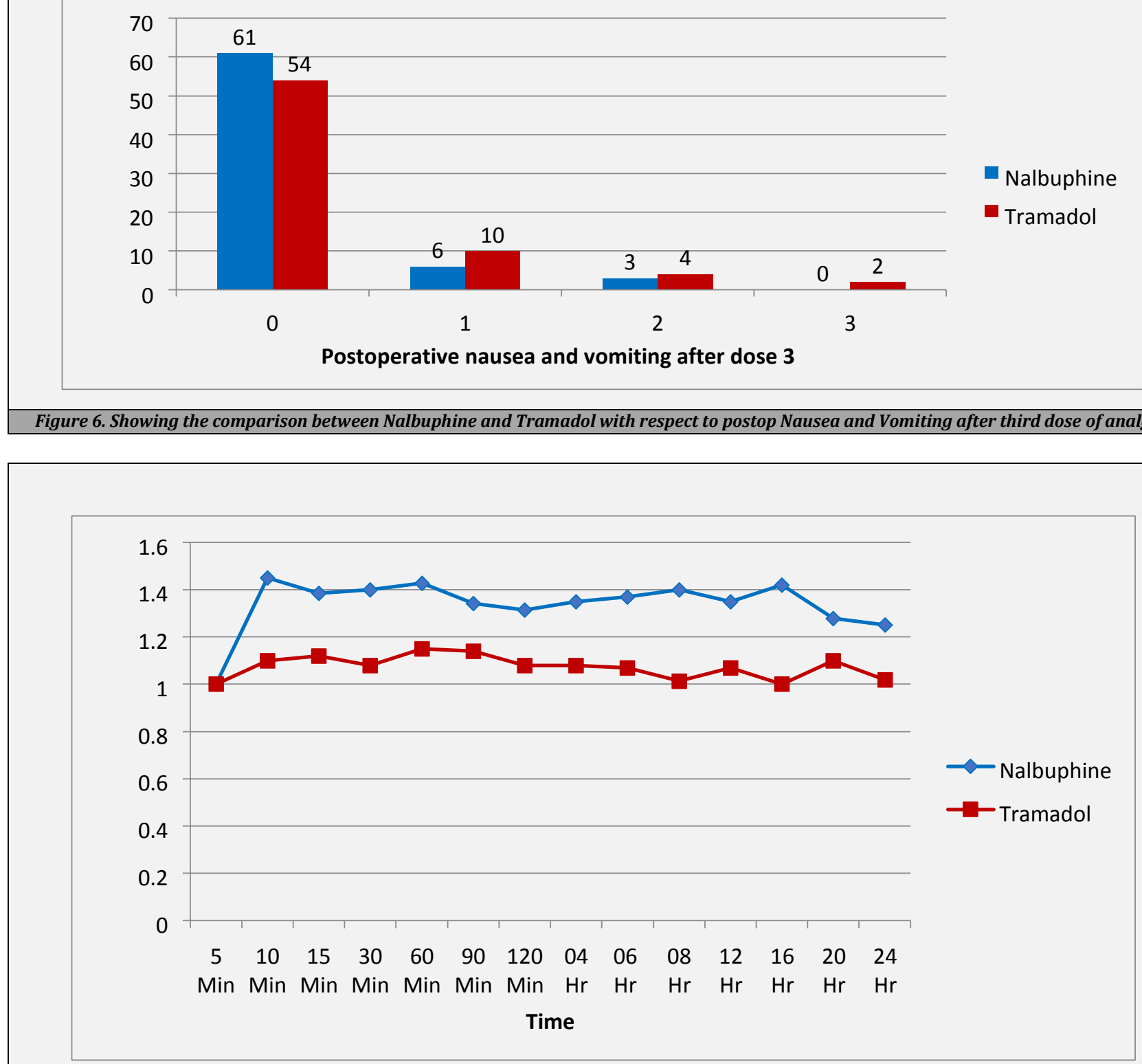

Figure 7. Showing the comparison between Nalbuphine and Tramadol with respect to Ramsay sedation score

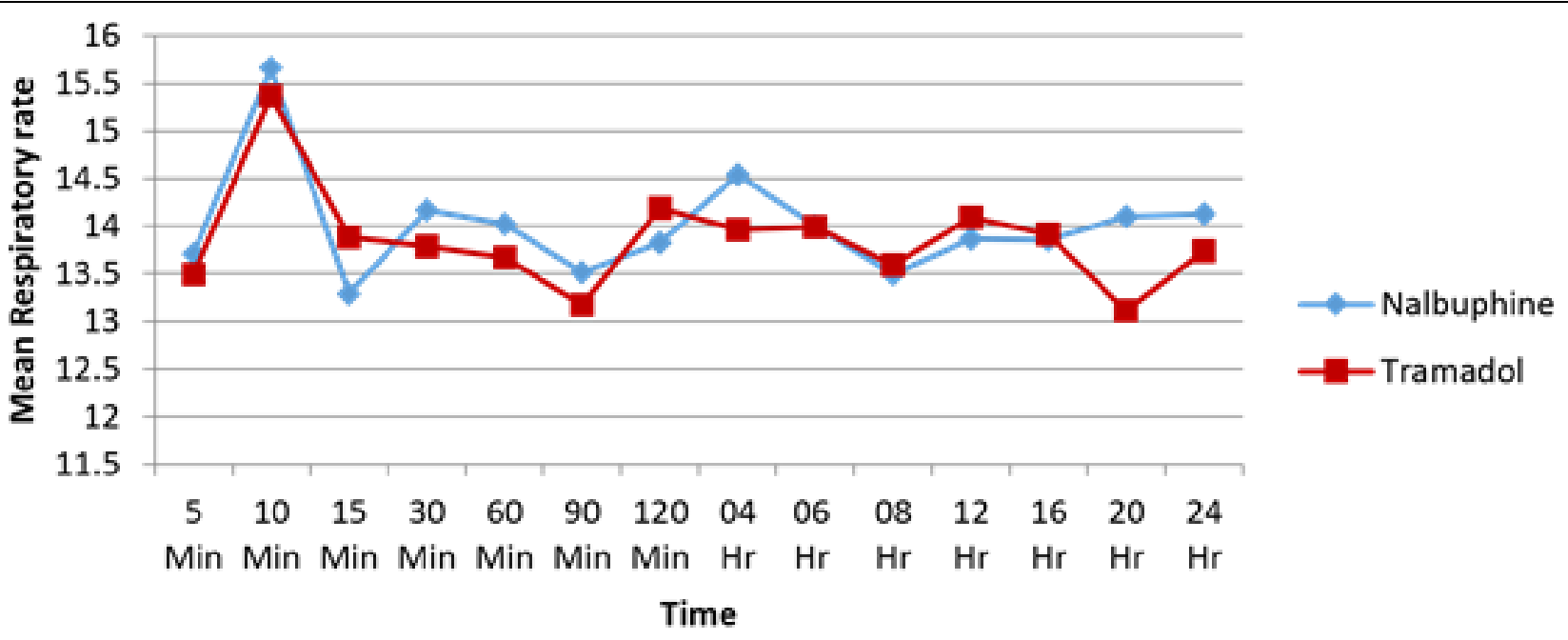




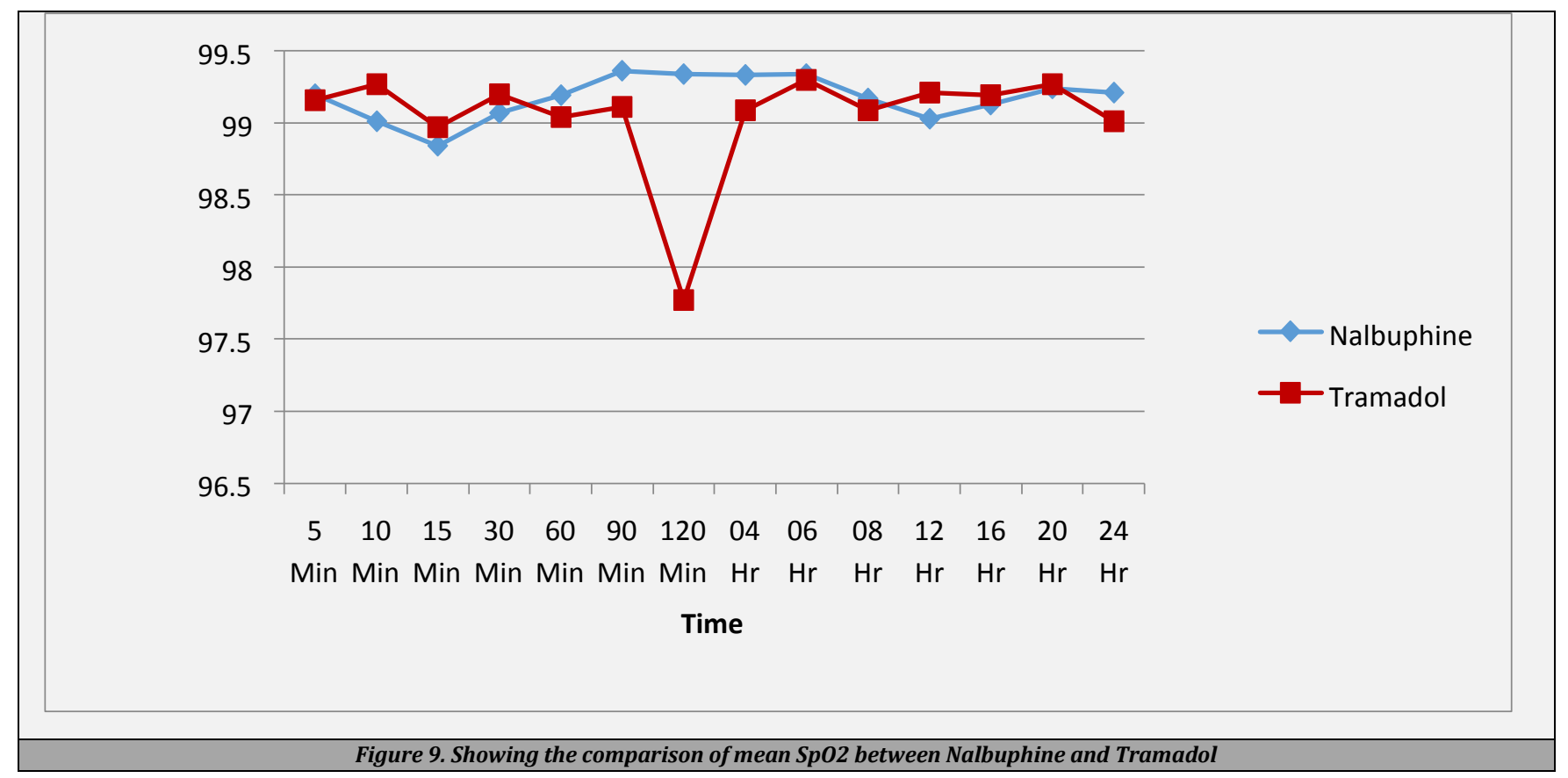

\section{DISCUSSION}

Mean VAS score for Nalbuphine at 10 mins 4.39 and Tramadol 3.36.VAS score statistically significant upto $6 \mathrm{hrs} p$ value $<0.05$. Tramadol has more reduction in VAS score compared to Nalbuphineupto 2 hrs. At 3 hrs VAS score Nalbuphine 2.58 and Tramadol 2.90.After 3 hrs VAS score for Nalbuphine at $4 \mathrm{hrs}, 5 \mathrm{hrs}$ and $6 \mathrm{hrs}$ are 2.30,1.91,3.41 respectivelyand for Tramadol 3.59,3.81 and 3.72 respectively. At 8 hrs p value $>0.05$ with mean VAS score 5.93 for Nalbuphine and 6.11 for Tramadol respectively. At $12 \mathrm{hrs}$ and 20 hrsagain statistically significant with $p$ value $<0.05$ with mean VAS score Nalbuphine 2.11 and 2.27 respectively and for Tramadol 3.09,2.84 respectively according to Mann whitney U test.

Rescue analgesic used was higher in Tramadol with maximum 4 doses in 13 patients whencompared to 6 patients in Nalbuphine group. But mean value for Nalbuphine 2.25 and forTramadol 3.05, it is not statistically significant with $\mathrm{p}$ value $>0.05$.

After the first dose of analgesia 13 patients in Tramadol group has nausea and 2 patients hasboth nausea and vomiting. But in Nalbuphine group none has vomiting complaints and only 7 patients have nausea. In 2nd and 3rd dose, nausea and vomiting incidence statisticallyinsignificant with $p$ value $>0.05$ but Tramadol has higher incidence of nausea and vomitingcompared to Nalbuphine group. Kumar et $\mathrm{al}^{27}$ found that pain scores on VAS were significantly less in nalbuphine groupafter 3rd postoperative hours, means nalbuphine had better pain control than tramadol.

Postoperative sedation score was comparable between group $\mathrm{N}$ and group $\mathrm{T}$ at 1 st hour butmean sedation scores were significantly more in group $\mathrm{N}$ at 2 nd and 4 th hour, none of thepatients of either group had sedation score more than 2. Mean duration of analgesia wassignificantly more in group $\mathrm{N}$ (6.3 \pm 0.7 hour) compared to group $\mathrm{T}(5.7 \pm 1.2$ hours).

Solanki et $\mathrm{al}^{5}$ did a study on comparison between Tramadol and Nalbuphine in Orthopaedicprocedures. Onset of drugs effect was found comparable after applying student's t-test,among both the groups. They also found that with successive doses it became significant andNalbuphine was proven to be having longer duration than Tramadol after 3rd dose (pvalue<0.005). Average sedation scores were significantly higher in Nalbuphine Group $(\mathrm{P}<0.0001)$ but none of the patient had a score higher than 2(often drowsy/easilyaroused). Further rescue analgesics used were significantly high in Tramadol Group withmaximum 4 doses used in 9 patients and in Nalbuphine Group maximum 4 doses were usedin 3 patients $(\mathrm{P}<0.0001)$ Tramadol has significant propensity towards nausea and vomiting $(<0.0001)$. Liaqat et $\mathrm{al}^{28}$ did a study involving 150 patients age ranges from 1-12yrs who underwentinguinal herniotomy. The mean pain score was lower in Nalbuphine group than in Tramadolgroup at 0 and $1 \mathrm{~h}(\mathrm{P}<0.05)$. However, at $4 \mathrm{~h}$ and 8 $\mathrm{h}$, the pain scores in Nalbuphine groupwere still lower, but not significantly. In all, 9 patients $(12.0 \%)$ required rescue analgesics in Nalbuphine group compared to 16 patients $(21.3 \%)$ in Tramadol group $(P=0.051)$. The meantime for requirement of rescue analgesics was $6.5 \pm 0.5 \mathrm{~h}$ in group $\mathrm{A}$ and $5.3 \pm 1.7 \mathrm{~h}$ in groupB $(\mathrm{P}=0.06)$.

Kiran et $\mathrm{al}^{29}$ identified that the Reduction in pain after drug administration was statisticallysignificant at all-time points as compared to before administration in both groups $(P<0.5)$. Pain reduction after $5 \mathrm{~min}(P=0.01)$ and $30 \mathrm{~min}(P$ $=0.03$ ) was significantly better withtramadol, whereas after 4 $\mathrm{h}$, it was better with nalbuphine $(P<0.05)$. Incidence of nausea andvomiting in tramadol and nalbuphine groups was $23.3 \%$ and $40 \%$, respectively. Nostatistically significant difference was observed in sedation, nausea, and vomiting scoresbetween two groups at any time point $(P>0.05)$.

Kamath ${ }^{30}$ et al found out that Percentage of pain relief was highly significant $(p<0.001)$ mean VAS score $0.72 \pm 0.64$ in nalbuphine group as compared with mean VAS score $1.72 \pm 0.75$ in tramadol group at $30 \mathrm{~min}$. Naeem ${ }^{31}$ et al did a study in which no significant difference was observed in term of painscore between oral Tramadol and intravenous Nalbuphine at 4 hours and 12 hours. At 8hours mean pain 
score in Tramadol group patients was $3.66 \pm 1.15$ and in Nalbuphine group itwas $2.96 \pm 1.36$, a significant difference was observed with p-value 0.021 .

Patients belonging to Nalbuphine group has mean respiratory rate ranging from 13.49 per minat baseline to 15.66 at $5 \mathrm{hrs}$ in postop.in Tramadol group the mean respiratory rate rangesfrom 13.83 at baseline to 15.37 per $\min$ at $5 \mathrm{hrs}$ in post op. The association between theintervention group and respiratory rate considered to be not statistically significant since pvalue $>0.05$ as per students t test.

Majority of Nalbuphine group patient had mean oxygen saturation ranging from $98.97 \%$ atbaseline to $99.97 \%$ at 24 hrs postop. The Tramadol group has mean Oxygen saturation from $98.87 \%$ at baseline to $99.09 \%$ at $24 \mathrm{hrs}$ in postop period. The association betweenintervention group and Oxygen saturation considered to be not statistically significant sincep $>0.05$ as per students $\mathrm{T}$ test.

Ouaki et $\mathrm{al}^{32}$ compared the analgesic efficacy and side effects of tramadol and nalbuphine, He found that no significant changes in respiratory rate. When Group $\mathrm{T}$ and Group $\mathrm{N}$ werecompared, Group $\mathrm{T}$ showed statistically significant sedating effect in $2,5,8,9,10,14,15,20,21,22$ hours $(\mathrm{p}<0.05)$.

Karthik $\mathrm{M}$ et $\mathrm{al}^{33}$ conducted a studygroup $\mathrm{T}$ showed statistically significant increase inrespiratory rate in $1,7,8$, $15,19,20,21$ hours over 24 hours $(\mathrm{p}<0.05)$. Group T showed post operative nausea, vomiting which is statistically significant in $1,7,8,15$ hours over 24 hourscompared to Group N.

Total Number of Doses Required Over 24 Hours Total number of doses required over 24 hours between Group T and group $\mathrm{N}$ was found to be $3.28 \pm 0.453$ and $3.16 \pm 0.37$ respectivelywith $\mathrm{p}=0.23$. Hence there was no statistically significant difference total number of dosesrequired over 24 hours in both groups.

Diana Moyao Garcia et $\mathrm{al}^{34}$ compared analgesic efficacy of nalbuphine versus tramadoladministered through continuous intravenous infusion for post op pain control found thatthere was increased incidence of vomiting in tramadol group.The comparison of sedation among Nalbuphine and Tramadol group based on Ramsaysedation score. Mean RSS in both the groups are comparable with $p$ value $>0.05$. No patientbelongs to Tramadol group has a score more than 2 compared to Nalbuphine.

Khalid Maudoodsiddiqui et al compared tramadol versus nalbuphine in total intravenousanaesthesia for dilatation and evacuation found that tramadol had more sedating effect thannalbuphine. Patients receiving nalbuphine woke up earlier and were well oriented comparedto tramadol.Time to orientation from the end of TIVA (min) 19.39 (5.7) for Nalbuphine and23.77 (7.8) for Tramadol. Time to opening of eyes from the end of TIVA (min) 8.39 (3.0) for Nalbuphine and 11.46 (3.8) Tramadol with $p$ value $<0.05$.

\section{Limitation}

Limitation in our study includes it is an observational methodology and thesample size in our study were not large enough to detect subtle differences.

\section{CONCLUSIONS}

Postoperative analgesia is the keystone of effective recovery from any surgery. Amongthe different agents tried so far, each have its own specific advantages anddisadvantages. From the various parameters compared and outlined in the study,showed that Nalbuphine appears to be better analgesic for the relief of moderate to severepostoperative pain in orthopaedic patients.

It provides good sedation and lower incidence of nausea \& vomiting compared to Tramadol.Both Nalbuphine and Tramadol can be a good alternative in the multimodal therapy of acutepost-operative analgesia.

Data sharing statement provided by the authors is available with the full text of this article at jemds.com.

Financial or other competing interests: None.

Disclosure forms provided by the authors are available with the full text of this article at jemds.com.

\section{REFERENCES}

[1] Akshat S, Ramachandran R, Rewari V, et al. Morphine versus nalbuphine for open gynaecological surgery: a randomized controlled double blinded trial. Pain Res Treat 2014;2014:727952.

[2] GanTJ. Poorly controlled postoperative pain: prevalence, consequences, and prevention. J Pain Res 2017;10:228798.

[3] Cunningham J, Temple WJ, Mitchell P, et al. Cooperative hernia study. Pain in the postrepair patient. Ann Surg 1996;224(5):598-602.

[4] Htun AT. A study on effectiveness of ilioinguinal and iliohypogastricnerve block at the time of wound closure for postoperative pain relief in inguinal hernia repair. J Pain Relief 2016;5:244.

[5] Solanki RN, Gosai ND, Joshi GM, et al. A comparative study of intravenous nalbuphine HCL and tramadol HCL for postoperative pain relief following orthopaedic surgeries. Asian Pac J Health Sci 2015;2(1):155-60.

[6] Joshi GP, Ogunnaike BO. Consequences of inadequate postoperative pain relief and chronic persistent postoperative pain. Anesthesiology Clinics of North America 2005;23(1):21-36.

[7] Covarrubias-Gómez A, González-García JL, BetancourtSandoval JA, et al. The perioperative acute pain and paracetamol: a view based in the evidence. Revista Mexicana de Anestesiología 2013;36(1):47-55.

[8] Kehlet $\mathrm{H}$, Holte K. Effect of postoperative analgesia on surgical outcome. Br J Anaesth 2001;87(1):62-72.

[9] Shamim F, Hoda MQ, Samad K, et al. Comparison between tramadol and pethidine in patient controlled intravenous analgesia. J Pak Med Assoc 2006;56(10):433-6.

[10] Raffa RB, Friderichs E, Reimann W, et al. Opioid and nonopioid components independently contribute to the mechanism of action of tramadol, an "atypical" opioid analgesic. J Pharmacol Exp Ther 1992;260(1):275-85.

[11] Lehmann KA. Tramadol in acute pain. Drugs 1997;53 Suppl 2:25-33. 
[12] Houmes RJ, Voets MA, Verkaaik A, et al. Efficacy and safety of tramadol versus morphine for moderate and severe postoperative pain with special regard to respiratory depression. Anesth Analg 1992;74(4):510-4.

[13] Lehmann KA, Kratzenberg U, Schroeder-Bark B, et al. Postoperative patient-controlled analgesia with tramadol: analgesic efficacy and minimum effective concentrations. Clin J Pain $1990 ; 6(3): 212-20$.

[14] Beaver WT, Feise GA. A comparison of the analgesic effect of intramuscular nalbuphine and morphine in patients with postoperative pain. J Pharmacol Exp Ther 1978;204(2):487-96.

[15] Miller RR. Evaluation of nalbuphine hydrochloride. American Journal of Hospital Pharmacy 1980;37(7):9429.

[16] Jaillon P, Gardin ME, Lecocq B, et al. Pharmacokinetics of nalbuphine in infants, young healthy volunteers, and elderly patients. Clin Pharmacol Ther 1989;46(2):22633.

[17] Ma HH, Chou TFA, Tsai SW, et al. The efficacy and safety of continuous versus single-injection popliteal sciatic nerve block in outpatient foot and ankle surgery: a systematic review and meta-analysis. BMC Musculoskelet Disord 2019;20(1):441.

[18] Ilfeld BM, Enneking FK. Continuous peripheral nerve blocks at home: a review. Anesth Analg 2005;100(6):1822-33.

[19] Ilfeld BM, Esener DE, Morey TE, et al. Ambulatory perineural infusion: the patients' perspective. Reg Anesth Pain Med 2003;28(5):418-23.

[20] Wu CL, Berenholtz SM, Pronovost PJ, et al. Systematic review and analysis of postdischarge symptoms after outpatient surgery. Anesthesiology 2002;96(4):9941003.

[21] Fortier J, Chung F, Su J. Unanticipated admission after ambulatory surgery--a prospective study. Can J Anaesth 1998;45(7):612-9.

[22] Chou LB, Wagner D, Witten DM, et al. Postoperative pain following foot and ankle surgery: a prospective study. Foot Ankle Int 2008;29(11):1063-8.

[23] Fung G, Liu SE. Regional anaesthesia for orthopaedic procedures. Anaesthesia \& Intensive Care Medicine 2020 Dec $10 \quad$ Available from: http://www.sciencedirect.com/science/article/pii/S147 2029920302411
[24] Alkire MT, Hudetz AG, Tononi G. Consciousness and anesthesia. Science 2008;322(5903):876-80.

[25] Bisson DL, Newell SD, Laxton C. Antenatal and postnatal analgesia. BJOG: An International Journal of Obstetrics \& Gynaecology 2019;126(4):e114-24.

[26] Alfieri S, Amid PK, Campanelli G, et al. International guidelines for prevention and management of postoperative chronic pain following inguinal hernia surgery. Hernia 2011;15(3):239-49.

[27] Kumar J, Sinha PK, Prasad BK, et al. Comparative study of nalbuphine and tramadol for postoperative pain relief in patients of short surgical procedures under TIVA. Int J Contemp Med Res 2017;4(4):977-99.

[28] Liaqat N, Dar SH. Comparison of single-dose nalbuphine versus tramadol for postoperative pain management in children: a randomized, controlled trial. Korean J Anesthesiol 2017;70(2):184-7.

[29] Kiran K, Vyas V, Patil S. Comparative efficacy and safety of intravenous tramadol and nalbuphine for pain relief in postoperative patients. Indian Journal of Pain 2018;32(2):96-6.

[30] Kamath SS, Kumar BCA, Upadya M, et al. A comparison of the analgesic effect of intravenous nalbuphine and tramadol in patients with post-operative pain - a double blind prospective randomised study. Asian J Pharm Health Sci 2013;3(3):677-8.

[31] Naeem AY, Fareed A, Nauman D, et al. Compare the analgesic efficacy of oral tramadol with intravenous analgesics on postoperative pain after caesarean section. Pak J Med Health Sci 2020;14:495-7.

[32] Ouaki J, Rochette A, Raux O, et al. Tramadol vsnalbuphine: analgesic efficacy and side effects. A prospective, randomized, double-blinded study in children: 10AP6-8. Eur J Anaesthesiol 2007;24(Suppl 39):138-9.

[33] Karthik M, Selvakumar R. A prospective randomized double blind study on postoperative pain relief in lower orthopedic surgeries comparison between intravenous Inj. Nalbuphine, Inj. Tramadol and Inj. Ketorolac. IJAA 2018;5(10):1654-61.

[34] Moyao-Garcia D, Hernández-Palacios J, Ramírez-Mora J, et al. A pilot study of nalbuphine versus tramadol administered through continuous intravenous infusion for postoperative pain control in children. Acta Biomed 2009;80(2):124-30. 